\title{
An Interview with Ruth Charney
}

\section{Evelyn Lamb}

Every other year, when a new AMS president takes office, the Notices publishes interviews with the outgoing and incoming presidents. What follows is an edited version of an interview with Ruth Charney, whose two-year term as president began on February 1, 2021. Charney is the Theodore and Evelyn Berenson Professor of Mathematics at Brandeis University. The interview was conducted in fall 2020 by freelance writer Evelyn Lamb.

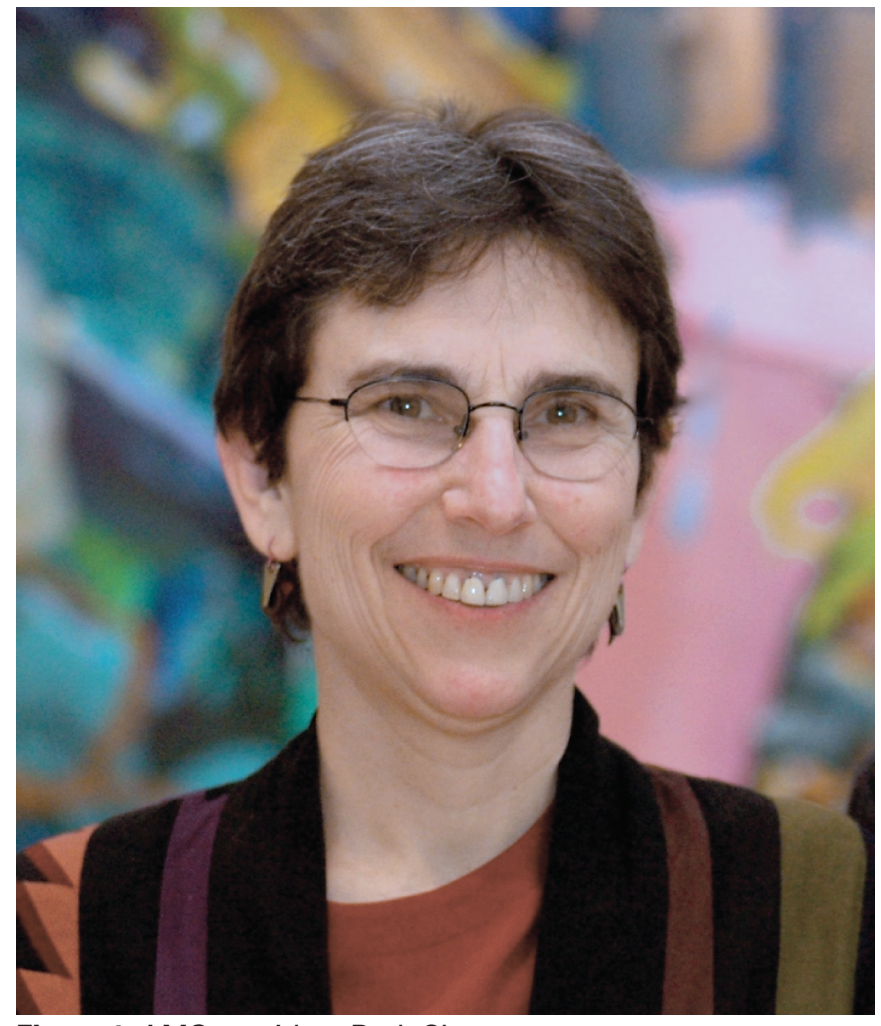

Figure 1. AMS president Ruth Charney.

Evelyn Lamb is a freelance writer in Salt Lake City, UT. Her email address is rootsofunityblog@gmai 1 .com.

For permission to reprint this article, please contact: reprint-permission aams.org.

DOI: https://dx.doi.org/10.1090/noti2228
Notices: Let's start with your academic history and how you got involved with the AMS.

Charney: Those are two slightly different things. I had a pretty standard academic history, I think. I was actually an undergraduate at Brandeis. It was a small school and only a few of the math majors planned to go on to graduate school. But it was very friendly, and I enjoyed my undergraduate years very much. After that, I took a gap year to study modern dance, and I had a great time, but the following year I went back to graduate school at Princeton. Then I had postdocs at Berkeley and Yale and eventually took a tenure-track job at Ohio State University. I spent the next 18 or 19 years of my career at Ohio State. Then in 2003, I moved to Brandeis. I have to say, I was very happy at Ohio State. The move had more to do with family issues: my husband's job and my mother, who was getting older and was alone in Vermont. I ended up moving back to my alma mater, Brandeis, and I've been there ever since. I think it's a pretty standard career path, nothing unusual about it, except that there were very few women in math at the time I started.

Notices: Can we go back to modern dance? That is a little bit of an unusual gap year for a mathematician.

Charney: I like to tell that story because it was a big part of me for a long time, and it isn't a part that most of the math community knows about. I started dancing in college; it's not something I did as a kid. I'd been in school all my life, and I planned to go on to graduate school. It wasn't that I didn't know what I wanted to do next; I just decided I needed a year off to do something different, and the one non-math thing I'd really been enjoying was dance. My 
sister was living in New York at the time, so I moved to New York to study dance for a year.

I was having such an amazing time dancing that I almost put off graduate school. I applied in the fall to graduate schools, and I got into a couple of schools, including Princeton, my first choice. I thought really hard about whether I could put this off for a year or two, because I was so enjoying myself. But I was afraid that if I didn't accept the offer to go to Princeton, I would regret it later. I think in the end, I realized that you can have a career in math and do dance as a hobby, while the other way around doesn't work very well. And that's totally what I did for many years. Eventually, after I had kids and then moved to Boston, the dance started to slide away. I'm not doing it anymore, although I keep saying I'm going to sign up for dance lessons again! But for a long, long time, it was my main passion outside of work.

\section{Notices: And how did you get involved in the AMS?}

Charney: I think my first serious involvement in professional societies was in 1990. I was asked to be on the AWM (Association for Women in Mathematics) Executive Committee. Two years later, I was elected as a member-atlarge of the AMS Council. So it was right in the early '90s that I got involved in both organizations, and frankly, since that time, I've always been at least on some professional committee. From 2006 to 2009, I was vice president of the AMS, and then I was on the Board of Trustees-I was very, very heavily involved. During that period, I also became president of the AWM. Then I took a brief break, and now here I am again. I can't seem to stay away from it!

I've thought a little bit about what got me involvedwhy I did it to begin with and why I continue to do it. And the obvious answer, which is certainly a factor, is that I felt that these organizations were doing something useful, and that I could contribute something. But I realize also that I was getting something out of it that I really liked. I liked connecting with a broader swath of the math community, hearing how different people saw different issues. I felt that I got a much broader picture of what was going on and a chance to meet interesting people.

Notices: And what skills and experience do you think you bring to the job of president?

Charney: In one sense, it's exactly what I said, a breadth of points of view. I've seen things from a lot of different sides and hopefully can bring that to the table. I've also been very involved with AMS itself, so I understand how AMS operates. Hopefully I can combine this experience with an awareness of some of the current issues that matter to people in the math community in a productive way.
Notices: And what are your priorities as you start serving your term as president?

Charney: I've been saying for years-and at this moment in time, it is particularly relevant-we made some real progress in bringing more women into mathematics and encouraging women already in the field. We're not at equality yet, but we've come a long way compared to what things were like when I started. Could we not refocus some of these ideas on other types of diversity and inclusion? Isn't it time to do that? The issues aren't exactly the same, but some of what we've learned from helping women get involved in mathematics and supporting them through their careers could be brought to bear on other types of diversity. If I had to choose one top priority, that would be it. I'm hoping my experience might prove useful, though I realize I'm going to need to talk to a lot of other people to get a better perspective and more ideas on how to address this problem.

We need to look at what the AMS can do. Issues of equality and inclusion have to be addressed at all different levels. You hear people say, “There aren't enough people from underrepresented groups to draw on. They're not even majoring in math. They're not even in our undergraduate classes. How are we supposed to fix this?" And then they blame the problem on K-12. And you know, it's easy to push the blame down. Absolutely, there have to be programs to address these problems in preschool and $\mathrm{K}-12$, but I think the AMS needs to look at what we are in a position to do. We are in a position to address the undergraduate to graduate to postdoc levels, moving people into careers in mathematics. That's where we can actually have

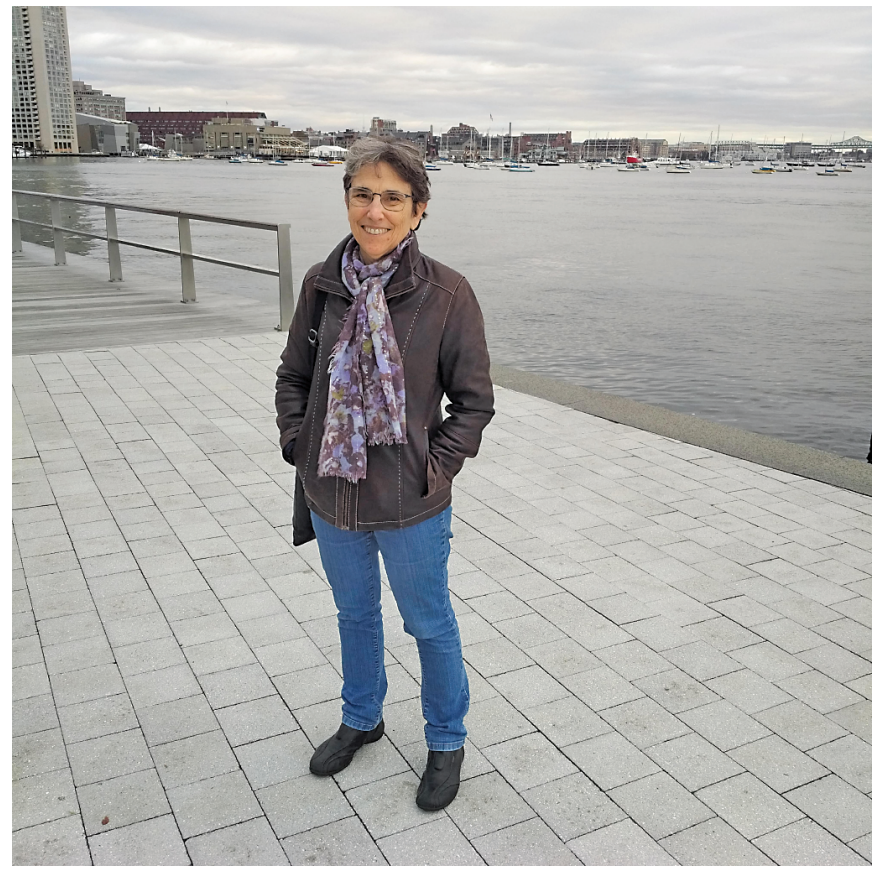

Figure 2. Ruth Charney in Boston in 2018. 
an effect. I don't have the answers to that, but I have some ideas. I look forward to discussing this with the new AMS Committee on Equity, Diversity and Inclusion.

Notices: It seems like you're taking over during a crisis moment in every area of life. COVID-19, of course, has sort of framed this whole year. How do you think you and the AMS will be responding to COVID-19 and the related crises that have come up since it started?

Charney: This is my opportunity to give a shout-out to Catherine Roberts, the executive director, and the whole AMS staff. They have been absolutely amazing. The pandemic has had major effects on meetings and on the functioning of the AMS. It's caused complications for the publishing business and for MathSciNet. I was pretty panicky at first, but I'm already feeling like things are under control. Yes, there are still challenges. Things are going to be different. There's not going to be an in-person JMM this year. I've always enjoyed the AMS meetings, especially the social part where you could just hang out, and there's not going to be as much of that for a while. But I feel like the "keeping things functioning part" is going well-the staff is amazing! Which means I get to focus on the issues that I was hoping to focus on. I won't be spending all my time trying to keep the ship from sinking.

Notices: Another aspect of the crisis, of course, is employment prospects for people who are graduating with PhDs or finishing their postdocs now. Are there ways the AMS can address that problem?

Charney: You're absolutely right. I do think this is a huge problem, and we do need to think about what, if anything, we can do. I have one postdoc and one graduate student both going on the job market this year, and it's very scary. There was discussion about this back in the days of the recession when there were similar sorts of problems. What could we do? One idea was to create more postdoctoral fellowships. The problem is that you can redirect something like the Centennial Fellowship to younger people or create a new fellowship or two, but that's only a fellowship or two. That's nice, but it's not broad enough. How can we affect a larger class? We have an office in Washington that does advocacy for us, to increase funding for NSF and so on. NSF could potentially create many new fellowships, while AMS could at best create one or two. Universities are all suffering right now. It's hard to know exactly where the effects are going to be felt most strongly. This is a huge problem. Various AMS committees are thinking about what else AMS could do in addition to advocacy. I wish I had answers to that.
Notices: As you said, part of the problem is that we don't know exactly what effects this crisis will have when all is said and done.

Charney: There's a lot of talk about whether this will change things in the long term, even after the virus is gone, and I think for some businesses it will. People are going to do less traveling, and there are definitely going to be changes, but I feel that people go to universities to get away from home, to change their world, not just to go to classes. I don't think that's going to disappear. I think that's going to come back to normal. Maybe there'll be a little more online teaching. When I taught at Ohio State University, I had some students who had children and a job, and they probably would have had an easier time if they could have done it remotely. But the students who come straight out of high school don't want to sit in their bedrooms and attend college by Zoom. I think universities are going to come back, and therefore faculty positions are going to come back. Maybe I'm being naive, but I hope that's correct.

Notices: And personally, did you have to scramble to start teaching online in the spring?

Charney: Yes, in the middle of the semester, we suddenly went online. That wasn't so hard for me. I was already through a large portion of the course material, so I recorded a few lectures, and then I switched over to having student presentations. I was teaching an undergraduate topology class, and I needed to cover the basic material. Then normally, I would have done something else fun, like the classification surfaces, perhaps. I decided instead to have the students give presentations on various applications of topology to make the class more interactive. This term, I'm teaching our first-year graduate course in algebraic topology, and it is totally online. The graduate students are all first-years, and they don't know each other. So even though I've taught the course a number of times before, I needed to think hard about how to make it work and how to get students to know each other. It's a challenge, and we'll get through it, but I don't know anybody who likes this style of teaching.

Notices: In the October issue of the Notices, there was a letter signed by at least 1,500 mathematicians encouraging their colleagues to boycott working with the police, which in the case of mathematicians often means creating predictive policing algorithms. The mathematical community is wrestling with the ethics of how mathematics is used in several different ways. Do you have any thoughts about that, both specifically the algorithms that are used in policing and then more broadly, the ethics of using mathematics in various application areas?

Charney: I'm hesitant to give my personal opinion, partly because I haven't thoroughly thought this through, and 


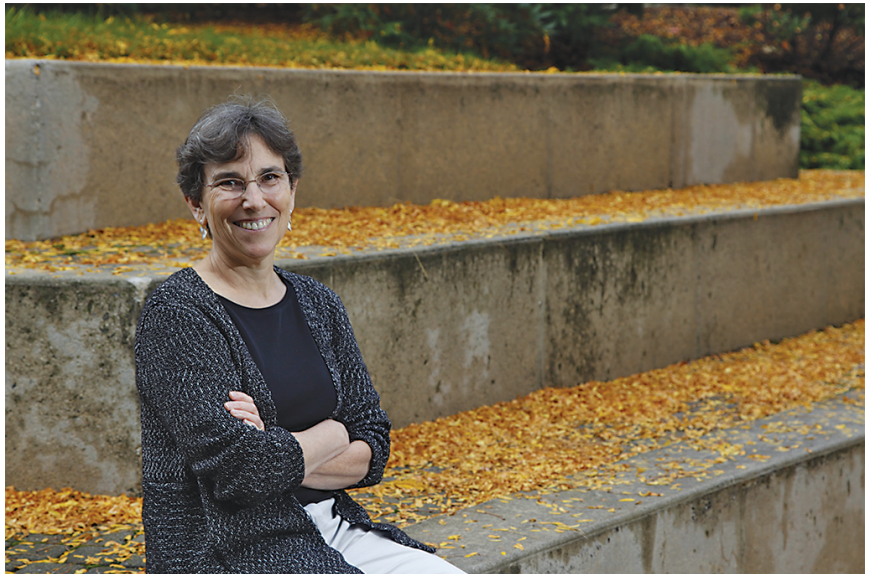

Figure 3. Ruth Charney on the Brandeis University campus in 2015.

also because I don't want to be speaking in the name of the AMS. You have to be careful when you're president, or president-elect, that there are your personal opinions and then there are the official opinions of the AMS. As far as the role of the AMS, what I'm happy to see is that there's a discussion going on because I think when there are issues that involve mathematics and the mathematical community that are controversial, that the AMS needs to facilitate a discussion, to let everybody speak out and see both sides of the story. As you say, there was this letter, but there have also been a number of responses that said, "Yes, but they're just going to use these algorithms anyway, and the results will get worse and worse if we don't tell them how to fix them." I actually see merit in both sides of the argument right now. Sometimes it is appropriate for the AMS to make a statement about something, but when that happens, it goes through discussion, it gets voted on by the Council, and then it becomes an official statement of the AMS. I think this is what the process has to be because no matter who you are, no matter how strongly you feel, this is the whole mathematical community talking.

I think it's really important that we recognize that these things are happening, and that we make people in the community aware of it, whether that means they stop working on these types of algorithms, or whether it means they get more involved, but in a way that helps improve them. I don't know which is the right answer, and maybe for some people it's one and for some the other. But I'm happy to see that this has become a topic that people are thinking about and talking about.

Notices: And you kind of addressed this, but maybe a better way I could have asked that question would be to ask when does it become appropriate for the AMS to make a statement about a broader issue in the country? I remember in July, in response to changes in F-1 visa regulations that would affect many international students, the AMS very quickly issued a statement and provided information about how members could contact their representatives and oppose those changes.

Charney: There is a way to bypass the full process, where it doesn't have to go through the whole Council. But only for things that are extremely timely and where there is a clear consensus in the math community, as there was with the visa regulations. Then you could short circuit the process. But I don't think this business on policing algorithms falls into that category.

Notices: Is there anything else you wanted to add?

Charney: There is something that concerns me-this certainly isn't a result of COVID, but maybe COVID made it worse-I don't really know. All of the professional societies for years now have been seeing a decrease in memberships. And I think that's because people can access anything online now. It used to be if you weren't a member, you didn't get this, or you didn't get that, and you felt out of touch. I hope people realize now that membership is about supporting the AMS, not just about going to a meeting for a slightly lower fee, or paying a little less for books. I would like people to recognize that what AMS does is really important to the mathematics community, and that they should support it because they believe in it.

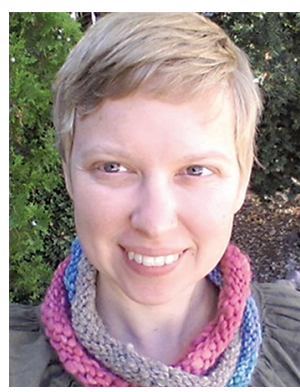

Evelyn Lamb

\section{Credits}

Figures 1 and 3 are by Mike Lovett for Brandeis University. Figure 2 is courtesy of Ruth Charney. Author photo is courtesy of Evelyn Lamb. 